\title{
The Effect of Strategic Flexibility on Strategy-Performance Nexus: A Conceptual Model
}

\author{
Liyanage A. S. ${ }^{1}$ and Weerasinghe T. D. ${ }^{2}$ \\ ${ }^{1}$ Institute of Trans Global Research, Sri Lanka \\ ${ }^{2}$ Department of Human Resource Management, \\ Faculty of Commerce and Management Studies, University of Kelaniya, Sri Lanka \\ ${ }^{1}$ liyanageayesh@gmail.com, 2tdtmdananjaya@gmail.com
}

\begin{abstract}
Many of the business strategies adopted by organizations fail as a result of inflexibility of such strategies in responding to market dynamics. Although there is a considerable number of research to indicate that the strategic clarity has a strong positive association with firm performance, there remains little theoretical and empirical evidence to explain the effect of strategic flexibility on firm performance. Hence, this concept paper draws on the Porter's typology and the Miles and Snow's typology to analyze how the strategic flexibility moderates the association between strategic clarity and firm performance. The paper concludes with a conceptual model that enables the testing of the discrete effect of strategic flexibility on firm performance which in turn will add insights to the said models in the study.
\end{abstract}

Keywords: Strategic Clarity; Strategic Flexibility; Firm Performance, Porter's Typology, Miles and Snow's Typology

\section{Introduction}

A large number of published studies can be found in the area of strategy-performance relationship (Parnell, 2013). Most of the studies have used a strategic group level of analysis to explain the business strategy-performance nexus (Leask \& Parker, 2007; Panagiotou, 2007; Parnell, 2008). It was identified as a middle ground between the industry and the firm levels of analysis (Porter, 1981). Even though each firm has a unique competitive strategy, strategic grouping identifies clusters of businesses using a common generic strategy. The ability to use combination business strategies presents a key business level concern that can be tested through a strategic group level of analysis (Parnell, 2010). Most of the studies have used Porter's (1980)

\footnotetext{
${ }^{2}$ https://orcid.org/0000-0001-5096-6696
} 
generic strategies and Miles and Snow's (1978) generic strategy typology to assess the strategyperformance relationship. However, Porter's approach does not consider long term combination strategies, hence investigations quickly expanded beyond Porter's (1980) typology to that of Miles and Snow (1978).

As scholars started to assess the relationship between strategy and performance, some studies supported the notion that pure cost leadership or differentiation strategies were associated with superior performance (Hambrick, 1982; Hawes \& Crittendon, 1984), whereas others concluded that combining cost leadership and differentiation could generate better results for businesses (Hill, 1988; Parnell, 1997; Parnell \& Wright, 1993). This ongoing debate has drawn the attention of many scholars and there are many empirical studies which address the strategyperformance nexus by considering the influence of other factors such as size of the firm, region, industry, innovation, organizational structure, flexibility of the strategy itself and etc. (Conant, Mokwa \& Varadarajan, 1990). A conclusion common to most published strategic group studies is that, firms lacking a coherent and consistent (reactors within the Miles \& Snow typology or firms stuck in the middle within the Porter's typology) strategic orientation are generally outperformed by other players in their respective industries. However, conclusions related to the adoption of more than one strategic orientation simultaneously have been inconsistent and elusive (Jusoh \& Parnell, 2008; Parnell \& Wright, 1993).

In the same context, Parnell (2010) came up with the construct of strategic clarity which has been conceptualized as the extent to which a business' efforts revolve around a single generic strategy. The findings of Parnell (2010) and Parnell (2013) largely contributed towards solving the strategy-performance conundrum in the presence of multiple strategic orientations simultaneously. However, most of these studies were based in USA and it's important to extend the studies to different industries and firms outside of the USA (Parnell, 2010). There is a clear dearth of studies in Asia on examining the strategy-performance relationship using Miles and Snow typology (Anwar, Shah \& Hasnu, 2016). In most of the studies, Asia represents countries like China, Turkey, Japan and Iran only. Out of these countries, only one study has used cluster analysis to identify the strategy-performance nexus. Further, there were no studies specifically in South Asia (India, Pakistan, Nepal, Sri Lanka and Bangladesh) that applies Miles and Snow typology to investigate strategy-performance nexus (Anwar et al., 2016).

It could be identified that a relatively lesser number of studies have tried to explain the effect of strategic clarity on firm performance whilst studying the moderating role of strategic 
flexibility. Surprisingly, there is a clear dearth of studies on strategy-performance nexus in a South Asian perspective (Anwar et al., 2016). Among such research studies which attempted to examine the strategy-performance relationship, there were no studies found in South Asia built on Miles and Snow typology.

Although the direct strategy-performance nexus is well documented, previous theoretical and empirical evidence of the relationship have been inconsistent and much remains to be learned specially in the presence of combination strategies (Parnell, 2010; Anwar et al., 2016). Further, there are no evidence of studies which have tested the moderating role of strategic flexibility on the relationship between strategic clarity and performance. Also, the Porter's model and the strategic-typology of Miles and Snow fail in explaining the role of strategic flexibility on the said relationship. This can be identified as a major theoretical gap in extant literature. Strategic flexibility is defined as the degree to which a firm is willing to change its strategy in response to opportunities, threats and changes in the external environment (Zahra et al., 2008). Moreover, Parnell (2010), found that firms with high strategic clarity outperformed those with moderate or low strategic clarity. Hence, the current study introduces a new construct of strategic flexibility to test the moderating effect of it on the aforementioned nexus.

Hence, having identified the lacuna in theoretical and empirical explanations up to date, the underline problem of the current concept paper is raised to investigate the impact of strategic clarity on firm performance which is moderated by strategic flexibility.

The rest of the paper is organized as follows. A brief overview of business strategies, business strategy typologies and strategy combinations is provided, and operational definitions of strategic clarity and strategic flexibility are outlined. The association between strategic clarity and firm performance is reviewed and the effect of strategic flexibility is analyzed. Finally, a conceptual model is proposed which states the relationship between strategic clarity, strategic flexibility and firm performance. Further, the limitations and implications of the model are presented.

\section{Literature Review}

\section{Business Strategy}

Strategy is about deliberately choosing to be different by making right choices or tradeoffs (Porter, 1985). As cited in Lin (2014), Porter (1996) identified strategy as a way of ensuring a sustainable competitive advantage by preserving what is distinctive about a business. The 
organizations use strategy to deal with changing business environments which bring novel combinations of circumstances and challenges to businesses. In strategy literature, corporate strategy and business strategy have been clearly differentiated. Firm or corporate level strategy reflects the boarder direction of a firm (growth, stability, retrenchment), whereas a business or competitive strategy means how a Strategic Business Unit (SBU) decides to compete within its industry (Parnell, 2010).

The assessment of business strategies can be traced back to the concept of Industrial Organization (IO) which is a branch of microeconomics. This industry-organization perspective identifies profitability as a function of industry structure (i.e. fragmented or consolidated). However, this model is considered to be more appropriate for industries with less complex group structures and relatively homogenous firms (Seth \& Thomas, 1994). Due to this inconsistency in previous research conclusions, many scholars have questioned the IO's ability to track large performance variances in a single industry. Therefore, strategic group level of analysis was proposed by many scholars as a middle ground between industry and firms (Porter, 1981).

Even though each firm has a unique competitive strategy, strategic group level of analysis identifies clusters of businesses who employ a similar generic strategy. Strategic groups can be defined as businesses within a same industry who seek to employ similar business strategies (Parnell, 2010). Identifying different strategic groups within an industry creates an excellent platform to examine the association of strategic characteristics with the firm performance. When identifying strategic groups within an industry, business strategy typologies are used as the basis to identify different clusters (Zahra \& Covin, 1993).

\section{Business Strategy Typologies}

Business strategy typologies are a kind of frameworks which identify multiple business strategies available to a business (Anwar et al., 2016). Typologies provide a theoretical basis to identify different strategic groups across industries (Parnell, 2011; Zamani et al., 2013). The typologies developed by Miles and Snow (1978) and Porter (1980) received much scholarly attention and remained among the most widely cited and tested models. Others have also proposed various strategy typologies, some are unique and some are based on previously developed models (Kim \& Mauborgne, 2005; Nwokah, 2008).

In Porter's (1980) framework the importance of having a deliberate strategy was emphasized. Porter's approach suggests that firms can achieve superior performance by either employing a 
cost leadership strategy (low costs) or differentiation strategy (differentiating its offering from that of competitors). Either of these strategies can be applied to a given market niche. Miles and Snow (1978) typology identified four types of strategic groups: Prospectors, defenders, analyzers and reactors. Prospectors are the innovators who perceive the environment as dynamic \& uncertain, and often they become the designers of the industry (Miles \& Snow, 1986). Defenders seek stability and operational excellence to achieve a maximum efficiency as they perceive the environment to be stable and certain. Analyzers focus to achieve both stability and flexibility at the same time. Reactors do not have a clear strategic choice and a direction, therefore perform poorly (Brunk, 2003).

Miles and Snow (1978) typology is considered to be a suitable framework to investigate strategy-performance nexus of firms from different industries having different firm size. This model has been well tested for its validity in a wide range of industries (Ghoshal, 2003; Hambrick, 2003) and it made the framework more popular among researchers. The wide use of Miles and Snow (1978) typology can be evidenced from its application by scholars in variety of industries including: financial industry (banks, insurance, mutual funds etc.); non-financial (manufacturing, chemical, electronics etc.) and service (hotels, hospitals, transportation etc.).

\section{Combination Strategy Debate}

Strategy-performance relationship has been examined by various studies in different contexts. However, most of the findings are inconclusive and inconsistent, and this has fueled the ongoing combination strategy debate. Porter's (1980) generic strategy is built on the economic principle of tradeoffs and it largely criticizes the presence of multiple strategic orientations which tend to be incompatible. Porter's (1980) approach was based on the notion that businesses who attempt to combine both low costs and differentiation invariably find itself 'stuck in the middle'. This ideology gained a considerable support in early studies (Hambrick, 1981, 1982; Hawes \& Crittendon, 1984), but was highly opposed in later studies (Hill, 1988; Parnell, 1997; Wright, 1987). Early studies used the Porter's framework to address the combination strategy debate, but investigations quickly moved towards Miles and Snow typology.

Later studies expanded beyond Porter's (1980) typology as it does not support for viable combination strategies in the long-run, whereas Miles and Snow's typology introduced analyzer to resolve that. Analyzer can be viewed as a hybrid strategy which focuses on both stability and flexibility (Parnell, 2010). Most of the studies which supported a single strategic 
orientation identified clear strategic groups and their relationship with the firm performance (Anwar et al., 2016). However, some scholars largely defended the notion of combination strategy and found its long term viability with superior performance (Hill, 1988; Parnell, 1997; Parnell \& Wright, 1993; Wright, 1987). Porter's original perspective on combination strategy was based on the notion that when businesses choose to pursue a one strategy, by definition they have to let go another. Scholars who support the concept of combination strategy acknowledge this idea to some extent, but they believe that the concept of tradeoffs are more accurate for relatively large industrial firms and industries with uncomplicated group structures (Seth \& Thomas, 1994).

\section{Strategic Clarity and Firm Performance}

Even though most of the strategy-performance studies have generated inconclusive and inconsistent results, below mentioned summary of key findings would be useful to establish the gap in existing knowledge and to state the propositions in the study. Most of the previous studies have supported the notion that firms with incoherent strategic orientation (i.e. firms stuck in the middle within Porter's typology and reactors within Miles and Snow's typology) are generally outperformed by other players in their respective industries. But, investigations concerning the adoption of multiple strategic orientations simultaneously have been ambiguous (Jusoh \& Parnell, 2008; Parnell \& Wright, 1993).

Strategy-performance studies applying Miles and Snow typology is extremely rare within the South Asian context (Anwar et al., 2016). In most of the studies Asia represents countries such as Japan, China, Turkey and Iran only. Except for these countries, only one study has used the financial data with cluster analysis technique in examining the strategy-performance linkage. The differences in performance among various strategic groups were largely due to the nature of performance measures and environments. For instance, prospectors outperformed defenders in terms of market share and defenders outperformed prospectors in terms of profitability (Hambrick, 1983). But a variation in conclusions can be seen in cross-country analysis under same studies (Parnell, Long \& Lester, 2015). Even though viable strategic groups (i.e. prospectors, defenders and analyzers) outperformed reactors, those strategies associated with negative performance in many occasions. For instance, prospectors didn't perform well in China and analyzers performed poorly in USA and Turkey (Parnell, 2012; Parnell et al., 2015).

Reactors performed poorly compared to other viable strategies in most of the instances. However, reactors performed well in highly regulated industries (Snow \& Hrebiniak, 1980) 
and in terms of Return on Assets (ROA) (Blackmore \& Nesbitt, 2013). These findings largely backed the argument by Zahra and Pearce (1990) that perceived inferiority of reactor strategy to other viable strategies is questionable. These inconclusive findings largely emphasize the significance of the current study as the proposed model will test the moderating role of strategic flexibility on the strategy-performance nexus. Perhaps, it may find answers to these inconclusive and inconsistent findings in up-to-date literature.

\section{Strategic Clarity}

Strategic clarity can be conceptualized as the extent to which a business avoids a stuck in the middle position by concentrating its productive efforts on supporting a single generic strategy (Parnell, 2010). To simplify, a firm with a high strategic clarity would only employ cost leadership or differentiation within the Porter's typology. It would employ a prospector, a defender or an analyzer generic strategy within Miles and Snow's typology. Although various studies have been conducted to examine the strategy-performance relationship, there are relatively lesser number of investigations that address the adoption of multiple strategic orientations simultaneously (Anwar et al., 2016). Moreover, according to findings of Parnell (2010), firms with a higher strategic clarity outperformed the ones with low or medium level of strategic clarity.

\section{Firm Performance}

Measuring the firm performance was identified as a key consideration in strategy-performance studies as the measurement scheme used for the study can substantially influence the results (Jusoh \& Parnell, 2008). Most of the early studies were based on financial measures, but later scholars focused on market-based performance measures as well (Kyriazis \& Anastassis, 2007). Qualitative measures of performance includes subjective areas such as satisfaction of customers, managers and ethical behavior etc. (Parnell et al., 2006). The present study would use both objective and subjective criteria in assessing the firm performance.

Hence, based on the reported evidence above, the following hypothesis is advanced:

\section{Hypothesis 1: Strategic clarity significantly effect on firm performance.}

\section{Strategic Flexibility}

Strategic flexibility can be identified as the degree to which a firm is ready to change its strategy in response to the opportunities, threats and changes in the external environment (Zahra et al., 2008, p.1043). Strategic flexibility helps businesses to sense critical changes in the 
environment (Grewal \& Tansuhaj, 2001), prevents organizational inertia (Zhou \& Wu, 2010) and boost creativity and innovation (Hitt et al., 1998). Thus, strategic flexibility may have an impact towards firm performance. However, published studies reflect mixed results regarding this phenomena. Many evidence support the notion that strategic flexibility improves the firm performance (Grewal \& Tansuhaj, 2001), whereas some studies have found out certain disadvantages of being strategically flexible such as high costs, increased stress, potential lack of strategic focus etc. (Das \& Elango, 1995).

Strategic flexibility is known to be an important source of competitive advantage in dynamic and challenging business environments (Hitt et al., 1998; Zahra et al., 2008). There are many studies that examine the relationship between strategic flexibility and firm performance, but an agreement on that relationship has not been fully reached (e.g. Grewal \& Tansuhaj, 2001). Inconsistent research findings reveal the fact that impact of strategic flexibility on firm performance can be context dependent (Grewal \& Tansuhaj, 2001). Hence, in the current study, strategic flexibility is suggested to be a moderator in the conceptual model. So that, the following hypothesis is advanced:

\section{Hypothesis 2: Strategic flexibility significantly moderates the effect of strategic} clarity on firm performance.

The above two hypotheses are illustrated in figure 01; the conceptual model. Strategic clarity is considered as the independent variable and firm performance is taken as the dependent variable. Strategic flexibility is suggested to be a moderator in the model.

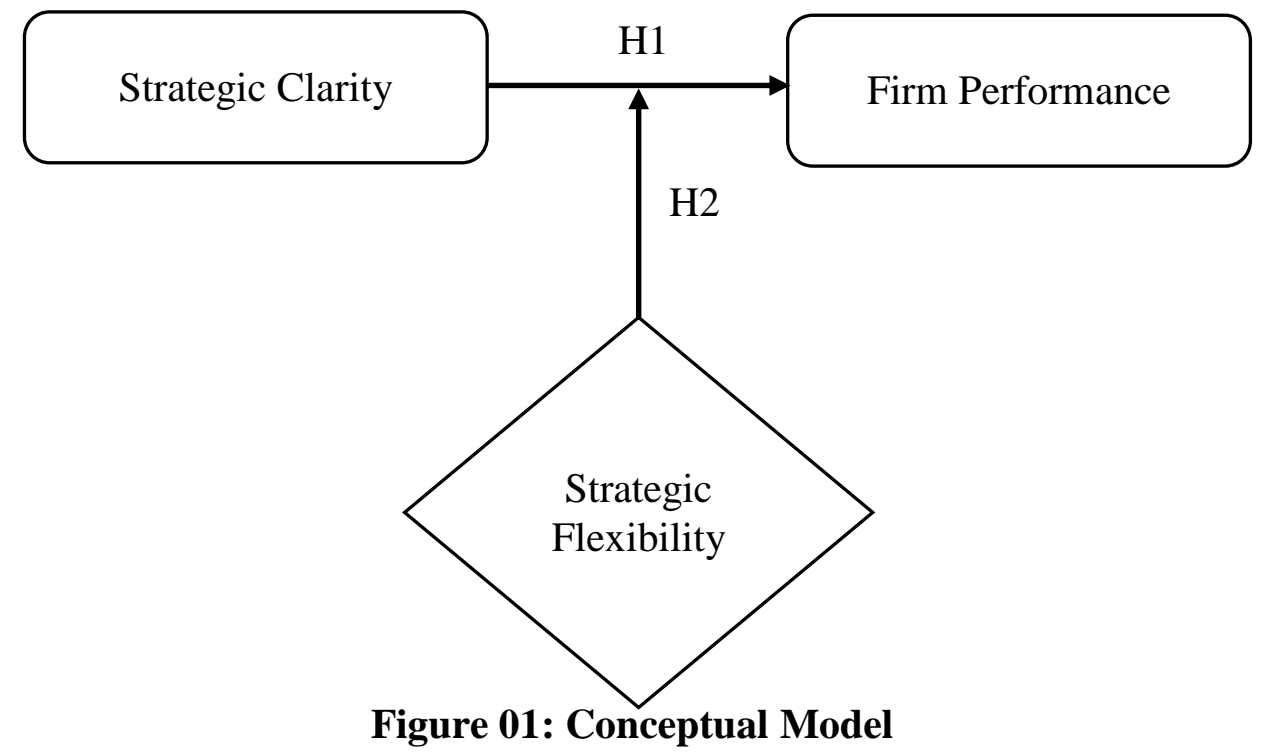

Source: Authors, 2018 


\section{Implications}

As mentioned, the current research will address the lacuna in empirical studies examining the effect of strategic clarity on firm performance whilst considering the moderating role of strategic flexibility in a South Asian Perspective. Hence, the study would bridge the empirical gap in the context. Further, the current study would provide empirical evidence to enrich the findings of Parnell (2010) and Parnell (2013) with a South Asian view. This study would generate a major theoretical contribution by examining the moderating role of strategic flexibility which has not been examined to explain the effect of strategic clarity on firm performance in extant literature. Perhaps, this study would justify the inadequacy of Porter's (1980) generic strategy typology which is built on the economic concept of tradeoffs, in which it believes the notion that firms should avoid pursuing multiple competitive strategies and focus on a one single generic strategy. Even though Porter's approach was later challenged extensively using various empirical studies (Eg: Buzzell \& Gale, 1987; Buzzell \& Wiersema, 1981; Hill, 1988; Parnell, 1997; Wright, 1987), no study has used the construct of strategic flexibility to explain the inadequacy of the typology.

The proposed study intends to examine the same in a South Asian perspective whilst considering the moderating role of strategic flexibility on the relationship between strategic clarity and firm performance. This would generate some new insights to resolve the contradicting conclusions in combination strategy literature by considering the moderating impact of strategic flexibility.

Further, the current study will provide insights for policy makers and strategists to achieve a more sustainable strategic orientation. South Asian region is considered to be the world's fastest growing region in the world (The World Bank, 2016). Hence, studies of this nature will help to improve the generalizability of USA based findings (Parnell, 2010), thus South Asian businesses also can use the insights of the current study to improve their strategic orientation. Applying Miles and Snow typology along with the technique of cluster analysis is extremely rare in the South Asian context (Anwar et al., 2016). Hence, the current study would have a strong theoretical and practical significance.

Although the strategic clarity is found to be a crucial antecedent of firm performance, there has been a very little attention given on strategic flexibility on the aforementioned association. The current paper develops a theoretical analysis to hypothesize the relationship between strategic clarity, strategic flexibility and firm performance. Hence, this concept paper bridges the lacuna 
on extant literature by plugging the construct of strategic flexibility to the model which explains firm performance.

\section{References}

Anwar, J., Shah, S. and Hasnu, S. (2016), "Business strategy and organizational performance: measures and relationships", Pakistan Economic and Social Review, Vol. 54 No 1, pp.97-122.

Blackmore, K. and K. Nesbitt (2013), Verifying the Miles and Snow strategy types in Australian small- and medium-size enterprises. Australian Journal of Management, Volume 38(1), pp. 171-190. https://doi.org/10.1177/0312896212444692

Brunk, S.E. (2003), “From theory to practice: applying Miles and Snow's ideas to understand and improve firm performance", Academy of Management Executive, Vol. 17 No. 4, pp. 105-8. https://doi.org/10.5465/ame.2003.11851877

Buzzell, R.D. and Gale, B.T. (1987), The PIMS Principles, Free Press, New York, NY.

Buzzell, R.D. and Wiersema, F.D. (1981), "Successful share building strategies", Harvard Business Review, Vol. 59 No. 1, pp. 135-44.

Capps, C.J. III, Jackson, G.K. and Hazen, S.E. (2002), "Strategic management synergy in the 21 stcentury", Journal of Applied Management and Entrepreneurship, Vol. 7 No. 1, pp. 76-93.

Conant, J.S., Mokwa, M.P. and Varadarajan, P.R. (1990), "Strategic types, distinctive marketing competencies and organizational performance: a multiple-measures-based study", Strategic Management Journal, Vol. 11, pp. 365-83. https://doi.org/10.1002/smj.4250110504

Das, T. and Elango, B. (1995), "Managing strategic flexibility: key to effective performance", Journal of General Management, Vol. 20, pp. 60-74. https://doi.org/10.1177/030630709502000305

Ghoshal, S. (2003), Miles and Snow: Enduring insights for managers. The Academy of Management Executive, Volume 17(4), pp. 109-114. https://doi.org/10.5465/ame.2003.11851879 
Grewal, R. and Tansuhaj, P. (2001), "Building organizational capabilities for managing economic crisis: the role of market orientation and strategic flexibility", Journal of Marketing, Vol. 65, pp. 67-80. https://doi.org/10.1509/jmkg.65.2.67.18259

Hambrick, D. C. (2003), On the staying power of defenders, analyzers, and prospectors. The Academy of Management Executive, Volume 17(4), pp. 115118. https://doi.org/10.5465/ame.2003.11851883

Hambrick, D.C. (1981), "Strategic awareness within top management teams", Strategic Management Journal, Vol. 2, pp. 263-79. https://doi.org/10.1002/smj.4250020305

Hambrick, D.C. (1982), "Environmental scanning and organizational strategy", Strategic Management Journal, Vol. 3, pp. 159-74. https://doi.org/10.1002/smj.4250030207

Hawes, J.M. and Crittendon, W.F. (1984), “A taxonomy of competitive retailing strategies", $\begin{array}{lllll}\text { Strategic Management Journal, } & \text { Vol. 5, }\end{array}$ https://doi.org/10.1002/smj.4250050307

Hill, C.W.L. (1988), "Differentiation versus low cost or differentiation and low cost: a contingency framework", Academy of Management Review, Vol. 13, pp. 401-12. https://doi.org/10.5465/amr.1988.4306957

Hitt, M.A., Keats, B.W. and DeMarie, S.M. (1998), "Navigating in the new competitive landscape: building strategic flexibility and competitive advantage in the 21 st century", Academy of Management Executive, Vol. 12, pp. 22-42. https://doi.org/10.5465/ame.1998.1333922

John A. Parnell, (2010),"Strategic clarity, business strategy and performance", Journal of Strategy and Management, Vol. 3 Iss 4 pp. 304 - 324. https://doi.org/10.1108/17554251011092683

Jusoh, R. and Parnell, J.A. (2008), “Competitive strategy and performance measurement in the Malaysian context: an exploratory study", Management Decision, Vol. 46, pp. 5-31. https://doi.org/10.1108/00251740810846716

Kim, W.C. and Mauborgne, R. (2005), Blue Ocean Strategy, Harvard Business School Press, Boston, MA. 
Kyriazis, D. and Anastassis, C. (2007), "The validity of the economic value added approach: an empirical application”, European Financial Management, Vol. 13 No. 1, pp. 71-100. https://doi.org/10.1111/j.1468-036X.2006.00286.x

Leask, G. and Parker, D. (2007), "Strategic groups, competitive groups and performance within the UK pharmaceutical industry: improving our understanding of the competitive process", Strategic Management Journal, Vol. 28, pp. 723-45. https://doi.org/10.1002/smj.603

Lin, C., Tsai, H. L. and Wu, J. C. (2014), Collaboration strategy decision-making using the Miles and Snow typology. Journal of Business Research, Volume 67(9), pp. 1979-1990. https://doi.org/10.1016/j.jbusres.2013.10.013

Mauri, A.J. and Michaels, M.P. (1998), "Firm and industry effects within strategic management: an empirical examination”, Strategic Management Review, Vol. 19, pp. 211-19. $\quad$ https://doi.org/10.1002/(SICI)1097-0266(199803)19:3<211::AID$\underline{\mathrm{SMJ} 947>3.0 . \mathrm{CO} ; 2-\mathrm{T}}$

Miles, R.E. and Snow, C.C. (1986), "Organizations: new concepts for new forms", California Management Review, Vol. 18 No. 3, pp. 62-73. https://doi.org/10.2307/41165202

Nwokah, N.G. (2008), "Strategic market orientation and business performance: the study of food and beverages organizations in Nigeria”, European Journal of Marketing, Vol. 42, pp. 279-86. https://doi.org/10.1108/03090560810852922

Panagiotou, G. (2007), "Reference theory: strategic groups and competitive benchmarking", Management Decision, Vol. 45, pp. 1595-621. https://doi.org/10.1108/00251740710837988

Parnell, J. A., Z. Long and D. Lester (2015), Competitive strategy, capabilities and uncertainty in small and medium sized enterprises (SMEs) in China and the United States. Management Decision, Volume 53(2), pp. 402-431. https://doi.org/10.1108/MD-04$\underline{2014-0222}$

Parnell, J.A. (1997), "New evidence in the generic strategy and business performance debate: a research note", British Journal of Management, Vol. 8, pp. 175-81. https://doi.org/10.1111/1467-8551.0049 
Parnell, J.A. (2008), "Strategy execution in emerging economies", Management Decision, Vol. 46, pp. 1277-98. https://doi.org/10.1108/00251740810911948

Parnell, J.A. (2010),"Strategic clarity, business strategy and performance", Journal of Strategy and Management, $\quad$ Vol. 3 Iss $4 \quad$ pp. $304 \quad-\quad 324$. https://doi.org/10.1108/17554251011092683

Parnell, J.A. (2013), “Uncertainty, generic strategy, strategic clarity, and performance of retail SMEs in Peru, Argentina, and the United States", Journal of Small Business Management, Vol. 51, pp. 215-234. https://doi.org/10.1111/jsbm.12010

Parnell, J.A. and Wright, P. (1993), "Generic strategy and performance: an empirical test of the Miles and Snow typology", British Journal of Management, Vol. 4 No. 1, pp. 29 36. https://doi.org/10.1111/j.1467-8551.1993.tb00159.x

Parnell, J.A., O’Regan, N. and Ghobadian, A. (2006), "Measuring performance in competitive strategy research", International Journal of Management and Decision Making, Vol. 7, pp. 408-17. https://doi.org/10.1504/IJMDM.2006.010246

Phillips, L.W., Chang, D.R. and Buzzell, R.D. (1983), "Product quality, cost position, and business performance: a test of some key hypotheses”, Journal of Marketing, Vol. 47 No. 2, pp. 26-43. https://doi.org/10.2307/1251491

Porter, M.E. (1980), Competitive Strategy, Free Press, New York, NY.

Porter, M.E. (1981), “The contributions of industrial organization to strategic management", Academy of Management Review, Vol. 6, pp. 609-20.

Porter, M.E. (1985), Competitive Advantage, Free Press, New York, NY.

Seth, A. and Thomas, H. (1994), "Theories of the firm: implications for strategy research", Journal of Management Studies, Vol. 31, pp. 165-91. https://doi.org/10.1111/j.1467$\underline{6486.1994 . t b 00770 . x}$

Ramanujam, V. and Venkatraman, N. (1987), "Planning system characteristics and planning effectiveness", Strategic Management Journal, Vol. 8, pp. 453-68. https://doi.org/10.1002/smj.4250080505 
Snow, C. C. and L. G. Hrebiniak (1980), Strategy, distinctive competence, and organizational performance. Administrative Science Quarterly, Volume 25(2), pp. 317-336. https://doi.org/10.2307/2392457

World Bank. (2016, April 10). South Asia Remains World's Fastest Growing Region, but Should Be Vigilant to Fading Tailwinds. Retrieved from: http://www.worldbank.org/en/news/press-release/2016/04/09/south-asia-fastestgrowing-region-world-vigilant-fading-tailwinds

Wright, P. (1987), “A refinement of Porter's strategies”, Strategic Management Journal, Vol. 8 No. 1, pp. 93-101. https://doi.org/10.1002/smj.4250080108

Zahra, S. A. and J. A. Pearce II (1990), Research evidence on Miles and Snow typology. Journal of Management, Volume 16(4), pp. 751-768. https://doi.org/10.1177/014920639001600407

Zahra, S.A. and Covin, J.G. (1993), "Business strategy, technology policy and firm performance", Strategic Management Journal, Vol. 14, pp. 451-78. https://doi.org/10.1002/smj.4250140605

Zahra, S.A., Hayton, J.C., Neubaum, D.O., Dibrell, C. and Craig, J. (2008), "Culture of family commitment and strategic flexibility: the moderating effect of stewardship", Entrepreneurship Theory and Practice, Vol. 32, pp. 1035-1054. https://doi.org/10.1111/j.1540-6520.2008.00271.x

Zamani, S., J. A., Parnell, H., Labbaf and O'Regan, N. (2013), Strategic change and decision making in an emerging nation: An exploratory assessment of Iranian manufacturing firms. Strategic Change, Volume 22(5-6), pp. 355-370.

Zhou, K.Z. and Wu, F. (2010), Technological capability, strategic flexibility, and product innovation, Strategic Management Journal, Vol. 31, pp. 547-561. https://doi.org/10.1002/jsc.1945 